\title{
Five-year Pan-European, longitudinal surveillance of Clostridium difficile ribotype prevalence and antimicrobial resistance: the extended ClosER study
}

\author{
Jane Freeman ${ }^{1,2} \cdot$ Jonathan Vernon $^{2} \cdot$ Sally Pilling ${ }^{2} \cdot$ Kirsti Morris $^{1} \cdot$ Scott Nicolson $^{2} \cdot$ Sharie Shearman $^{2}$. \\ Emma Clark $^{2}$ - Jose Alejandro Palacios-Fabrega ${ }^{3} \cdot$ Mark Wilcox $^{1,2} \cdot$ the Pan-European Longitudinal Surveillance of \\ Antibiotic Resistance among Prevalent Clostridium difficile Ribotypes' Study Group
}

Received: 10 May 2019 / Accepted: 11 September 2019 /Published online: 7 December 2019

(C) The Author(s) 2019

\begin{abstract}
Clostridium difficile infection (CDI) has been primarily treated with metronidazole or vancomycin. High recurrence rates, the emergence of epidemic PCR ribotypes (RTs) and the introduction of fidaxomicin in Europe in 2011 necessitate surveillance of antimicrobial resistance and CDI epidemiology. The ClosER study monitored antimicrobial susceptibility and geographical distribution of $C$. difficile RTs pre- and post-fidaxomicin introduction. From 2011 to 2016, 28 European countries submitted isolates or faecal samples for determination of PCR ribotype, toxin status and minimal inhibitory concentrations (MICs) of metronidazole, vancomycin, rifampicin, fidaxomicin, moxifloxacin, clindamycin, imipenem, chloramphenicol and tigecycline. RT diversity scores for each country were calculated and mean MIC results used to generate cumulative resistant scores (CRSs) for each isolate and country. From 40 sites, 3499 isolates were analysed, of which 95\% (3338/3499) were toxin positive. The most common of the 264 RTs isolated was RT027 (mean prevalence 11.4\%); however, RT prevalence varied greatly between countries and between years. The fidaxomicin geometric mean MIC for years $1-5$ was $0.04 \mathrm{mg} / \mathrm{L}$; only one fidaxomicin-resistant isolate (RT344) was submitted (MIC $\geq 4 \mathrm{mg} / \mathrm{L}$ ). Metronidazole and vancomycin geometric mean MICs were $0.46 \mathrm{mg} / \mathrm{L}$ and $0.70 \mathrm{mg} / \mathrm{L}$, respectively. Of prevalent RTs, RT027, RT017 and RT012 demonstrated resistance or reduced susceptibility to multiple antimicrobials. RT diversity was inversely correlated with mean CRS for individual countries (Pearson coefficient $r=-0.57$ ). Overall, C. difficile RT prevalence remained stable in 2011-2016. Fidaxomicin susceptibility, including in RT027, was maintained post-introduction. Reduced ribotype diversity in individual countries was associated with increased antimicrobial resistance.
\end{abstract}

Keywords Clostridium difficile $\cdot$ Ribotype prevalence $\cdot$ Antimicrobial susceptibility $\cdot$ Antimicrobial resistance $\cdot$ Surveillance

Electronic supplementary material The online version of this article (https://doi.org/10.1007/s10096-019-03708-7) contains supplementary material, which is available to authorized users.

Jane Freeman

jane.freeman4@nhs.net

1 Department of Microbiology, Leeds Teaching Hospitals Trust, Leeds, UK

2 Healthcare Associated Infections Research Group, The Leeds Institute of Medical Research, University of Leeds, Leeds, UK

3 Astellas Pharma, Inc., Chertsey, UK

\section{Introduction}

Clostridium difficile infection (CDI) represents a major healthcare burden in the developed world [18]. Metronidazole and vancomycin have been the mainstays of CDI treatment in recent decades [24]; however, high recurrence rates and reports of reduced susceptibility to metronidazole among epidemic $C$. difficile PCR ribotypes (RTs) have highlighted the need for new agents [1, 24]. Fidaxomicin is a macrocyclic antibiotic with low MICs against $C$. difficile, approved by the EMA in 2011 for the treatment of CDI in adults [7]. In two phase 3, double-blind, randomized, parallelgroup trials, it demonstrated non-inferiority in initial cure of CDI and lower rates of recurrence, compared with oral vancomycin [5, 15]. Fidaxomicin is also 
associated with greater preservation of the intestinal microbiota compared with vancomycin [14].

The aims of the 5-year ClosER study (2011-2016) were to identify and monitor the longitudinal antimicrobial susceptibility of $C$. difficile clinical isolates, including those previously implicated in selection pressure, to establish a comprehensive susceptibility database baseline for ongoing surveillance and to provide data on the geographical distribution of clinical $C$. difficile strain types across Europe.

\section{Methods}

ClosER was a Pan-European, multicentre, in vitro surveillance study, planned to provide data for 1 year prior to the introduction of fidaxomicin (July 2011-June 2012) and 2 years post-introduction (2012-2014). It was subsequently extended for a further 2 years (2014-2016). Participating centres were mostly national or regional C. difficile referral laboratories selected using the European Study Group on Clostridium difficile (ESGCD) network and with ESGCD approval. The number of sites approached per country was based on population (1 site per 15 million population) or reported incidence of CDI ( $\geq 2$ sites for countries with $>20$ cases per 10,000 patient days per hospital). Fifty-one sites from 28 European countries were asked to participate. Criteria for site inclusion were active sampling and testing for CDI, sufficient numbers of clinical CDI cases to reach a target of 25 de-duplicated cases during the 6-month collection period and a willingness to submit the required number of samples over the 3 years. The 40 sites that contributed samples during years 1-3 were contacted to request their participation in years 4 and 5 of the study. Of these, 28 sites agreed to participate in the extended study, three sites formally ended their participation after year 3 , and nine sites were unresponsive.

Isolates or faecal samples were submitted to a central laboratory (Leeds, UK) for PCR ribotyping, determination of toxin status and assessment of susceptibility to metronidazole, vancomycin, rifampicin, fidaxomicin, moxifloxacin, clindamycin, imipenem, chloramphenicol and tigecycline, using methods described previously [9, 10] (Online Resource 1). Participating sites were asked to provide the following demographic data to accompany each sample: age, gender, history of CDI in the previous 6 months, healthcare or community CDI episode, and antimicrobial administration 1 month prior to the episode.

RT diversity and Cumulative Resistance Scores were calculated each year for individual countries (Online Resource 1).

\section{Results}

\section{Submissions}

Across the 5 years of the study, a total of 3656 faecal samples or $C$. difficile isolates were submitted, yielding 3499 isolates of which $95 \%(n=3338)$ were toxin positive (Table 1$)$. Only six countries participated in all years of the study: Czech Republic, France, Germany, Ireland, Spain and the UK. Preliminary data for year 1 and complete data for years $1-3$ have been published previously $[9,10]$.

In any given year, less than one-quarter of sites submitted complete demographic datasets (Table 1). Prior occurrence of CDI was indicated for $418(19.4 \%)$ of the 2154 samples for which information was available. There was a degree of variation between RTs with regard to prior occurrence of CDI (Table 2); however, these data should be interpreted with caution due to the lack of information for the majority of samples. Complete antimicrobial treatment data was received from $<30 \%$ of sites in each year of the study; analysis was, therefore, not performed on these data due to the potential for bias in the use of incomplete information.

\section{PCR ribotype prevalence and distribution}

Across years 1, 2, 3, 4 and 5 of the study, there were 114, 144, 120, 107 and 66 respective known PCR RTs isolated, making a total of 264 distinct RTs. The most commonly isolated RTs (prevalence $\geq 1 \%$ ) in all years are listed in Table 3. RT prevalence and diversity scores varied markedly between countries and between each year of the study (Fig. 1a-e).

\section{Ribotype prevalence and distribution}

RT prevalence results for years 1-3 have been described in detail previously $[9,10]$. RT027 was the most commonly isolated RT at a mean prevalence of $11.4 \%$ across years $1-5$ (Table 3). RT027 was highly prevalent in Poland for all years that submissions were received (years 1-3) and in Hungary in year 1. In Cyprus, its prevalence increased each year from $28 \%$ in year 1 to $89 \%$ in year 4 (no submissions were received from Cyprus in year 5). For countries that provided samples in all 5 years of the study, although fluctuations were apparent, the most prevalent RTs remained broadly consistent between 2011 and 2016 (Online Resource 2).

\section{Ribotype diversity}

RT diversity varied between countries and between years (Fig. 2). The highest overall RT diversity was seen in Belgium (RT diversity scores $0.96,0.84$ and 0.92 for years 1, 2 and 4, respectively). Although high scores were also 
Table 1 Numbers of participating sites and submissions received over years 1-5 of the ClosER study

\begin{tabular}{|c|c|c|c|c|c|c|c|}
\hline \multirow[t]{2}{*}{ Year } & \multirow[t]{2}{*}{$\begin{array}{l}\text { Number of } \\
\text { participating sites }\end{array}$} & \multirow[t]{2}{*}{$\begin{array}{l}\text { Complete demographic } \\
\text { data, } n / N(\%)\end{array}$} & \multicolumn{2}{|c|}{$\begin{array}{l}\text { Antimicrobial } \\
\text { treatment data, } \\
n / N(\%)\end{array}$} & \multirow[t]{2}{*}{$\begin{array}{l}\text { Submissions } \\
\text { received }\end{array}$} & \multirow[t]{2}{*}{$\begin{array}{l}\text { C. difficile-positive } \\
\text { isolates }\end{array}$} & \multirow[t]{2}{*}{$\begin{array}{l}\text { Toxin-positive } \\
\text { isolates, } n / N(\%)\end{array}$} \\
\hline & & & Datasets & $\begin{array}{l}\text { Complete } \\
\text { datasets }\end{array}$ & & & \\
\hline 1 & 39 & 7/39 (17.9) & $14 / 39(35.9)$ & $3 / 39(7.7)$ & 978 & 944 & $897 / 944(95.0)$ \\
\hline 2 & 40 & $6 / 40(15.0)$ & $16 / 40(40.0)$ & $7 / 40(17.5)$ & 1003 & 948 & $910 / 948(96.0)$ \\
\hline 3 & 33 & $7 / 33(21.2)$ & $19 / 33(57.6)$ & $9 / 33(27.3)$ & 846 & 808 & $770 / 808(95.3)$ \\
\hline 4 & 23 & $2 / 23(8.7)$ & $10 / 23(43.5)$ & $1 / 23(4.3)$ & 575 & 560 & $529 / 560(94.5)$ \\
\hline 5 & 7 & $1 / 7(14.3)$ & $3 / 7(42.9)$ & $0 / 7(0)$ & 254 & 239 & $232 / 239(97.1)$ \\
\hline Total & - & - & - & - & 3656 & 3499 & $3338 / 3499(95.4)$ \\
\hline
\end{tabular}

Fifty-one sites in total were initially contacted. Submissions include both isolates and faecal samples

found for Bulgaria, it was omitted from this analysis due to the very low sample numbers submitted each year.

\section{Antimicrobial susceptibility}

\section{Fidaxomicin}

Almost all isolates from years 1 to 5 were susceptible to $\leq 1 \mathrm{mg} / \mathrm{L}$ fidaxomicin (Online Resource 3; Online Resource 4; Online Resource 5), with an overall geometric mean MIC of $0.04 \mathrm{mg} / \mathrm{L}$ across all years of the study. A single fidaxomicin-resistant isolate ( $\mathrm{MIC} \geq 4 \mathrm{mg} / \mathrm{L}$ ) was obtained in France in year 5 and found to be RT344. All other RT344 isolates $(n=5)$ were susceptible to fidaxomicin (MIC 0.004 $0.5 \mathrm{mg} / \mathrm{L})$ (Online Resource 6).

Fidaxomicin MICs were highest for RT198 at 0.04$0.10 \mathrm{mg} / \mathrm{L}$ over years $1-4$. No RT198 was isolated in year 5 . Fidaxomicin MICs for RT027 isolates varied between 0.02 and $0.08 \mathrm{mg} / \mathrm{L}$ over years $1-5$. RT017, which was associated with the most isolates with multiple antimicrobial resistance in years 1, 2, 3 and 5 (see below), had MICs of 0.01-0.05 mg/L and showed no sign of reduced susceptibility to fidaxomicin. Similarly, RT012 had the most multiple antimicrobialresistant isolates in year 4 but showed no sign of reduced susceptibility to fidaxomicin (MIC $0.03-0.05 \mathrm{mg} / \mathrm{L}$ ). There was also no evidence of reduced susceptibility among newly emergent RTs with multiple antimicrobial resistance, such as

Table 2 Proportions of the most prevalent ribotypes $(n>70)$ isolated over years $1-5$ of the ClosER study, by gender, age group, source and previous CDI history

\begin{tabular}{|c|c|c|c|c|c|c|c|c|c|c|c|c|c|}
\hline \multirow[t]{2}{*}{ Ribotype } & \multicolumn{2}{|c|}{ Gender, $\%(N=2577)$} & \multirow[t]{2}{*}{$\begin{array}{l}\text { Median age } \\
\text { (years) }\end{array}$} & \multicolumn{6}{|c|}{ Age in years, $\%(N=2460)$} & \multicolumn{2}{|c|}{ Source, \% $(N=2269)$} & \multicolumn{2}{|c|}{$\begin{array}{l}\text { Prior CDI, } \\
\%(N=2154)\end{array}$} \\
\hline & Male & Female & & $<1$ & $1-18$ & $19-44$ & $45-64$ & $65-84$ & $\geq 85$ & $\begin{array}{l}\text { Community } \\
\text { acquired }\end{array}$ & $\begin{array}{l}\text { Hospital } \\
\text { acquired }\end{array}$ & No & Yes \\
\hline 027 & 46.56 & 53.44 & 77 & 0.00 & 0.43 & 3.85 & 14.96 & 58.12 & 22.65 & 20.4 & 72.9 & 65.1 & 26.0 \\
\hline 014 & 41.18 & 58.82 & 71 & 1.44 & 2.40 & 9.62 & 20.67 & 44.71 & 21.15 & 23.6 & 67.0 & 67.9 & 23.9 \\
\hline 001 & 47.00 & 53.00 & 73 & 0.97 & 1.94 & 9.71 & 20.87 & 53.40 & 13.11 & 9.9 & 79.7 & 79.3 & 12.4 \\
\hline 078 & 49.69 & 50.31 & 73 & 0.42 & 6.28 & 14.64 & 33.89 & 14.64 & 30.13 & 24.3 & 70.3 & 73.1 & 18.6 \\
\hline 002 & 46.73 & 53.27 & 68 & 1.77 & 2.65 & 15.04 & 20.35 & 50.44 & 9.73 & 24.7 & 66.3 & 75.0 & 14.8 \\
\hline 020 & 49.59 & 50.41 & 69 & 3.31 & 7.44 & 14.05 & 16.53 & 43.80 & 14.88 & 17.5 & 76.3 & 70.3 & 22.5 \\
\hline 005 & 46.75 & 43.25 & 72 & 0.87 & 2.61 & 24.35 & 32.17 & 30.43 & 9.57 & 22.1 & 75.0 & 70.6 & 17.6 \\
\hline 126 & 57.45 & 42.55 & 73 & 1.27 & 1.27 & 8.86 & 35.44 & 31.65 & 21.52 & 14.1 & 83.5 & 73.3 & 23.3 \\
\hline 015 & 46.75 & 44.87 & 70 & 9.20 & 5.75 & 16.09 & 20.69 & 28.74 & 19.54 & 31.9 & 62.3 & 84.5 & 12.7 \\
\hline All isolates & 46.91 & 53.08 & 71 & 1.42 & 9.75 & 7.44 & 15.01 & 30.87 & 35.52 & 20.4 & 72.9 & 73.8 & 19.5 \\
\hline
\end{tabular}


Table 3 Percentage prevalence (> 1\%) of C. difficile PCR ribotypes in years 1-5 of the ClosER study

\begin{tabular}{|c|c|c|c|c|c|c|c|c|c|c|c|c|c|c|c|c|c|}
\hline \multicolumn{3}{|c|}{ Year 1} & \multicolumn{3}{|c|}{ Year 2} & \multicolumn{3}{|c|}{ Year 3} & \multicolumn{3}{|c|}{ Year 4} & \multicolumn{3}{|c|}{ Year 5} & \multicolumn{3}{|l|}{ Total } \\
\hline RT & $n$ & $\begin{array}{l}\text { Prevalence, } \\
\%\end{array}$ & RT & $n$ & $\begin{array}{l}\text { Prevalence, } \\
\%\end{array}$ & RT & $n$ & $\begin{array}{l}\text { Prevalence, } \\
\%\end{array}$ & RT & $n$ & $\begin{array}{l}\text { Prevalence, } \\
\%\end{array}$ & $\mathrm{RT}$ & $n$ & $\begin{array}{l}\text { Prevalence, } \\
\%\end{array}$ & RT & $n$ & $\begin{array}{l}\text { Prevalence, } \\
\%\end{array}$ \\
\hline 027 & 115 & 12.2 & 027 & 112 & 11.8 & 027 & 101 & 12.6 & 027 & 65 & 11.3 & 014 & 30 & 11.8 & 027 & 404 & 11.4 \\
\hline 001 & 86 & 9.1 & 014 & 89 & 9.4 & 014 & 85 & 10.6 & 001 & 43 & 7.5 & 106 & 21 & 8.3 & 014 & 321 & 9.1 \\
\hline 078 & 76 & 8.1 & 001 & 77 & 8.1 & 001 & 63 & 7.8 & 014 & 43 & 7.5 & 002 & 20 & 7.9 & 001 & 283 & 8.0 \\
\hline 014 & 74 & 7.8 & 002 & 53 & 5.6 & 020 & 44 & 5.5 & 078 & 39 & 6.8 & 078 & 20 & 7.9 & 078 & 231 & 6.5 \\
\hline 020 & 38 & 4.0 & 078 & 53 & 5.6 & 078 & 43 & 5.4 & 002 & 32 & 5.6 & 001 & 13 & 5.1 & 002 & 175 & 4.9 \\
\hline 126 & 35 & 3.7 & 020 & 49 & 5.2 & 126 & 41 & 5.1 & 020 & 24 & 4.2 & 020 & 13 & 5.1 & 020 & 168 & 4.7 \\
\hline 002 & 34 & 3.6 & 005 & 31 & 3.3 & 002 & 35 & 4.4 & 005 & 22 & 3.8 & 027 & 11 & 4.3 & 005 & 122 & 3.4 \\
\hline 015 & 32 & 3.4 & 015 & 31 & 3.3 & 005 & 31 & 3.9 & 015 & 21 & 3.7 & 176 & 8 & 3.1 & 126 & 121 & 3.4 \\
\hline 005 & 31 & 3.3 & 126 & 31 & 3.3 & 015 & 22 & 2.7 & 012 & 15 & 2.6 & 005 & 7 & 2.8 & 015 & 112 & 3.2 \\
\hline 106 & 24 & 2.5 & 018 & 28 & 3.0 & 046 & 19 & 2.4 & 039 & 11 & 1.9 & 015 & 6 & 2.4 & 106 & 85 & 2.4 \\
\hline 023 & 23 & 2.4 & 023 & 20 & 2.1 & 106 & 18 & 2.2 & 003 & 10 & 1.7 & 017 & 6 & 2.4 & 018 & 69 & 1.9 \\
\hline 018 & 21 & 2.2 & 017 & 18 & 1.9 & 017 & 15 & 1.9 & 070 & 9 & 1.6 & 126 & 6 & 2.4 & 017 & 62 & 1.7 \\
\hline 356 & 21 & 2.2 & 046 & 17 & 1.8 & 176 & 13 & 1.6 & 106 & 9 & 1.6 & 023 & 5 & 2.0 & 023 & 61 & 1.7 \\
\hline 012 & 19 & 2.0 & 012 & 14 & 1.5 & 018 & 12 & 1.5 & 176 & 9 & 1.6 & 050 & 5 & 2.0 & 012 & 60 & 1.7 \\
\hline 011 & 16 & 1.7 & 198 & 14 & 1.5 & 003 & 11 & 1.4 & 018 & 8 & 1.4 & 081 & 5 & 2.0 & 046 & 58 & 1.6 \\
\hline 017 & 16 & 1.7 & 106 & 13 & 1.4 & 010 & 11 & 1.4 & 126 & 8 & 1.4 & 070 & 4 & 1.6 & 176 & 47 & 1.3 \\
\hline 046 & 15 & 1.6 & 056 & 11 & 1.2 & 081 & 11 & 1.4 & 017 & 7 & 1.2 & 012 & 3 & 1.2 & 011 & 40 & 1.1 \\
\hline 087 & 15 & 1.6 & 029 & 10 & 1.1 & 011 & 10 & 1.2 & 043 & 7 & 1.2 & 013 & 3 & 1.2 & 081 & 39 & 1.1 \\
\hline 056 & 11 & 1.2 & 039 & 10 & 1.1 & 023 & 10 & 1.2 & 010 & 6 & 1.0 & 056 & 3 & 1.2 & 003 & 35 & 1.0 \\
\hline \multirow[t]{4}{*}{ Other } & 241 & 25.5 & 081 & 10 & 1.1 & 070 & 10 & 1.2 & 013 & 6 & 1.0 & 154 & 3 & 1.2 & 070 & 35 & 1.0 \\
\hline & & & Other & 257 & 27.1 & 012 & 9 & 1.1 & 054 & 6 & 1.0 & Other & 58 & 22.8 & 198 & 35 & 1.0 \\
\hline & & & & & & 198 & 8 & 1.0 & 198 & 6 & 1.0 & & & & Other & 960 & 27.3 \\
\hline & & & & & & Other & 180 & 22.4 & Other & 160 & 27.9 & & & & & & \\
\hline
\end{tabular}

RT356 and RT018, which are closely related RTs with MICs of $0.03-0.05 \mathrm{mg} / \mathrm{L}$ over the years that these were isolated.

\section{Metronidazole and vancomycin}

Metronidazole and vancomycin were highly active with very little variation in sensitive, intermediate and resistant isolates over years 1-4. Geometric mean MICs for years 1-5 were $0.46 \mathrm{mg} / \mathrm{L}$ and $0.70 \mathrm{mg} / \mathrm{L}$ for metronidazole and vancomycin, respectively. Reduced metronidazole susceptibility was mainly observed in RT027 and RT198 (Online Resource 4). Although vancomycin MICs above the geometric mean were observed in RT018 (years 1 and 4) and RT356 (years 1 and 3) from Italy, geometric mean vancomycin MICs for these RTs were similar to those for all isolates in other years (Online Resource 4). Geometric mean vancomycin MICs also increased in RT126 from $0.66 \mathrm{mg} / \mathrm{L}$ in year 1 to $1.00 \mathrm{mg} / \mathrm{L}$ in Year 5 .

\section{Rifampicin}

Numbers of isolates resistant to rifampicin decreased slightly over the course of the study from $13.5 \%$ in year 1 to 10.2 $11.8 \%$ in years $4-5$ (Online Resource 3 ). The more prevalent RTs $027,198,018,356,017$ and 176 had notably high proportions of rifampicin resistance.

\section{Moxifloxacin and clindamycin}

Resistance to both moxifloxacin and clindamycin was common and evident in all participating countries but varied between years and between countries (Online Resource 3; Online Resource 4). For example, clindamycin resistance in the Czech Republic fluctuated between 24 and 63\% during the study.

\section{Imipenem, chloramphenicol and tigecycline}

The majority of isolates in all years were susceptible to imipenem, and the highest geometric mean MICs were found for RT176 (10.37 mg/L, year 5) and RT017 (10.56 mg/L, year 3) (Online Resource 4). The majority of isolates were susceptible to chloramphenicol, but higher geometric mean MICs were observed in RT001 and RT017. Reduced susceptibility to tigecycline (MIC $>0.25 \mathrm{mg} / \mathrm{L}$ ) was also scarce; however, geometric mean MICs were marginally elevated in RT012.

\section{Multiple antimicrobial resistance}

Of the prevalent RTs, RT027 consistently demonstrated resistance or reduced susceptibility to metronidazole, rifampicin, moxifloxacin and imipenem, while RT001 had consistently elevated geometric mean moxifloxacin, 

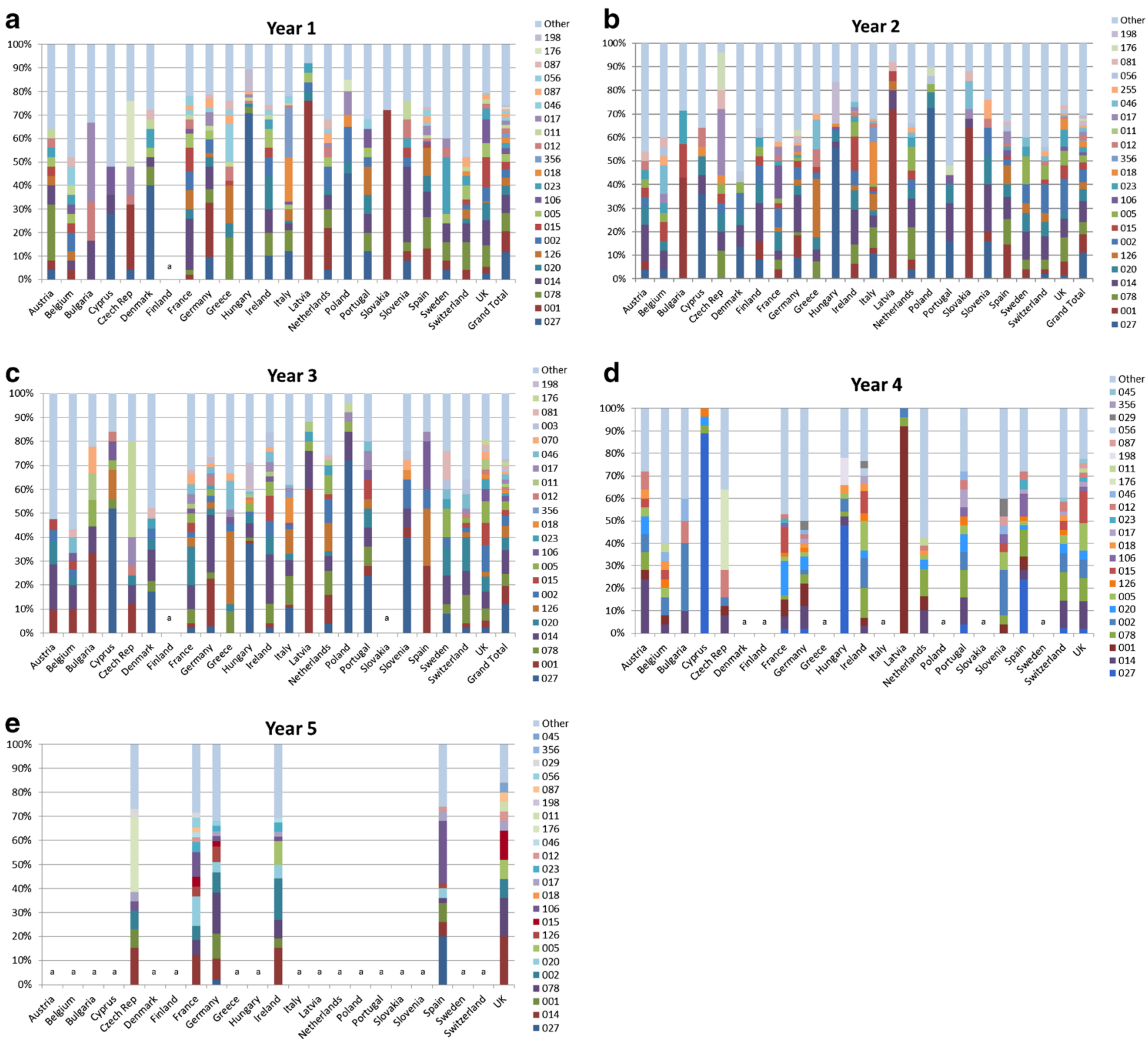

Fig. 1 Percentage prevalence by country of $C$. difficile PCR ribotypes in a year 1, b year 2, $\mathbf{c}$ year 3, d year 4 and $\mathbf{e}$ year 5 of the ClosER study. ${ }^{\text {Na }}$ submissions received from this country. Other $=$ all other ribotypes with prevalence $<1 \%$

clindamycin and chloramphenicol MICs. Other prevalent RTs showed reduced susceptibility to multiple antimicrobials. Some RT017 isolates had elevated geometric mean rifampicin, moxifloxacin and clindamycin MICs in years 1 and 4 and elevated imipenem and chloramphenicol MICs in years 2, 3 and 5. RT017 in years 1-3 and year 5 , plus RT012 in year 4, demonstrated resistance to the broadest range of antimicrobials tested.

\section{Antimicrobial susceptibility by country}

Of the countries that submitted data for all 5 years of the study, Ireland and the UK showed generally reducing CRS over the first 4 years of the study, increasing slightly in year 5 (year 1:
Ireland 2.26, UK 2.16; year 4: Ireland 0.87, UK 0.49; year 5: Ireland 1.22, UK 1.25) (Online Resource 7). When all countries included in the study were analysed, there was a significant inverse correlation between RT diversity and mean CRS for individual countries (Pearson coefficient $r=-0.57$; correlation significance $p=0.004$ ) (Online Resource 8). This indicated lower antimicrobial resistance levels in countries with a greater $C$. difficile RT diversity.

\section{Discussion}

To date, this is the largest Pan-European study of $C$. difficile RT prevalence and antimicrobial resistance. Almost 3500 
Fig. 2 Ribotype diversity by country during years $1-5$ of the ClosER study

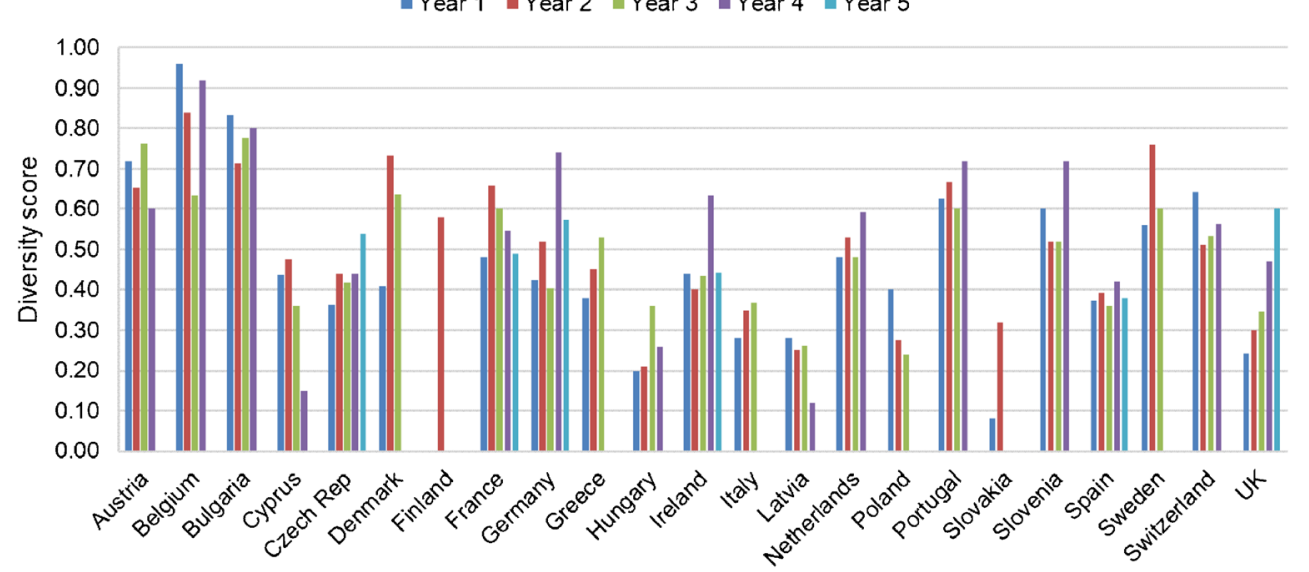

isolates were received, yielding 264 distinct RTs. Over the first 4 years of the study, the prevalence of the 10 most common RTs remained stable and the changes observed in year 5 should be interpreted with caution due to a substantially reduced number of submissions and participating countries. The most prevalent RTs found in our study correspond closely to those previously reported in 2011 [3] and 2016 [6], indicating overall stability in RT prevalence over time. Some fluctuation in relative RT prevalence between years and between countries was observed, as expected due to endemic and epidemic spread of $C$. difficile [8]. Previously described epidemic or highly prevalent RTs, such as 014, 027, 001 and 078, remained highly prevalent in this study. RT005, RT087 and RT356 were more prevalent in year 1 than previously observed [3], but of these, only RT005 remained highly prevalent throughout the study.

Fidaxomicin MICs remained consistently low throughout the 5 years of the study, and there was no evidence of a reduction in susceptibility following its introduction in 2011. This is consistent with an earlier antimicrobial susceptibility survey of isolates from two phase III studies of 1164 patients that reported fidaxomicin MIC90s of $0.25 \mathrm{mg} / \mathrm{L}$ [11]. The same survey identified a single strain of $C$. difficile from a patient with recurrence with a fidaxomicin MIC of $16 \mathrm{mg} / \mathrm{L}$; however, the relatedness of the pre- and post-treatment strains was not determined [11], and the association of resistance with drug exposure cannot be made definitively [21]. Schwanbeck et al. described fidaxomicin resistance (MIC $>64 \mathrm{mg} / \mathrm{L}$ ), associated with a V1143D mutation in rpoB, in a single clinical $C$. difficile isolate of 50 isolates tested [19]; however, the fitness burden imposed by the mutation was higher when generated in vitro $[13,19]$ than observed in the clinical isolate [19]. In the light of high fidaxomicin gut concentrations, the significance of this is unclear but highlights the need for further monitoring. We report a single fidaxomicin-resistant isolate of RT344 (MIC $\geq 4 \mathrm{mg} / \mathrm{L}$ ), isolated in year 5 of the study; this isolate was also resistant to moxifloxacin, clindamycin and imipenem, but sensitive to all other antimicrobials tested. All other RT344 isolates submitted were susceptible to fidaxomicin.

RT027, the most prevalent RT in the ClosER study, has previously been associated with multiple antimicrobial resistance [17] and reduced susceptibility to fidaxomicin compared with other PCR ribotypes (MIC90s $0.5 \mathrm{mg} / \mathrm{L}$ versus $\leq 0.25 \mathrm{mg} / \mathrm{L}$, respectively) [11]. However, no such association was found in the ClosER study. The geometric mean fidaxomicin MIC for the RT027 isolates submitted to this study $(0.04-0.08 \mathrm{mg} / \mathrm{L})$ was below the susceptibility breakpoint. Likewise, RT017, 012, 018 and 356 showed resistance to multiple antimicrobials in this study but were not associated with higher fidaxomicin MICs. Moreover, the clinical significance of RT-specific variations in fidaxomicin susceptibility is questionable, particularly given the high concentrations of fidaxomicin $(>1000 \mu \mathrm{g} / \mathrm{g})$ attained in the gut [20].

While susceptibility to fidaxomicin remained stable over years $1-5$, susceptibility to metronidazole and vancomycin increased. This could be attributed to a reduction in metronidazole and vancomycin use and/or greater strain diversity. The present study confirmed previously reported associations between prevalent RTs, such as RT027 and RT001, and resistance to moxifloxacin, clindamycin and chloramphenicol [2, $16,22]$. However, there were examples of these RTs from many countries showing almost full susceptibility to all agents. Imipenem resistance is not well-documented for C. difficile, but we found evidence of both intermediate and full resistance in all years.

Fluctuations in antimicrobial susceptibility between countries and between years are reflective of the varying prevalence of RTs. Multiple antimicrobial resistance was most evident in certain epidemic RTs, such as RT027 and 001, but was also notable in RT017, RT012, emerging RT198 (exclusive to Hungary) and RT356 (exclusive to Italy). We found a consistent inverse correlation between RT diversity and mean CRS 
for a given country, possibly due to the introduction of mandatory reporting programmes with a subsequent increase in awareness, antimicrobial stewardship and infection control interventions reducing rates of endemic RTs.

The selection criteria for submissions stipulated 25 deduplicated toxin-positive faecal samples or $C$. difficile isolates, with no further requirements. There may, therefore, be selection bias in the samples submitted from any location. Participating centres were mainly national or regional $C$. difficile reference facilities and, therefore, some submissions likely included outbreak strains, possibly influencing the data. The majority of submissions were isolates rather than faecal samples. The recovery rate was generally poorer from faecal samples (mean $86 \%$; median $84 \%$ ) than from isolates (mean 97\%; median $100 \%)$. In years 1 and 2, three sites submitted faecal samples, with recovery rates between 64 and $100 \%$. In years 3 and 4, two of these sites submitted isolates: for one of these sites, recovery rates increased to $100 \%$ in both years, while for the other site, recovery rates increased to $84 \%$ and $92 \%$ in years 3 and 4 , respectively.

We advised sites on how to prepare isolates as spores for transport but did not obtain information on whether this advice had been followed. We experienced consistently poor C. difficile recovery from isolate submissions by one site during all 3 years of their participation (76\%, 40\% and 52\%). Another site had a recovery rate of $100 \%$ in year 1 , but this rate dropped to $88 \%$ and $82 \%$ for years 2 and 3, respectively, after changing to different transport conditions. It was notable that all of these were not submitted as advised in transport media, and it is possible that this contributed to the poor recovery rates. However, these sites were not the only participating locations from their country ( 1 of 3 and 1 of 4, respectively) and, therefore, the effect of low recovery rates was lessened somewhat. Despite these site-specific limitations, overall recovery rates were $>96 \%$ for $90 \%, 83 \%, 85 \%$ and $91 \%$ of sites in years 1, 2, 3 and 4 , respectively.

There was a substantial decrease in the responsiveness of sites, and consequently the number of submissions, during years 4 and 5. Possible reasons for a lack of response included site staff resourcing issues, the extended duration of the study and the loss or retirement of named site contacts or national coordinators. Although sample transport was provided, courier transport was problematic in some countries and there was no financial incentive for sites to submit samples. In year 5, only the Czech Republic, France, Germany, Ireland, Spain and the UK submitted isolates. From the UK, only one site submitted samples in year 5 , while all four sites consistently submitted samples in years $1-4$. Countries with high RT027 prevalence were, therefore, not represented in year 5 , skewing the data. Accompanying patient data, particularly information on antimicrobial treatment, was often missing.

\section{Conclusions}

Overall ribotype prevalence across Europe remained stable between 2011 and 2016, and a lack of ribotype diversity in an individual country was associated with greater antimicrobial resistance. There was no evidence of reduced susceptibility to fidaxomicin following its introduction in 2011. The identification of emerging and highly antimicrobial-resistant C. difficile PCR ribotypes highlights the importance of continued surveillance.

Acknowledgements We would like to thank the following ClosER study participants: Franz Allerberger, Sabine Pfeiffer, Anita Fiedler, Steliana Huhulescu and Markus Hell (Austria); Michel Delmée, Kate Soumillion, Johann van Broeck and Eléonore Ngyuvulu Mantu (Belgium); Kate Ivanova and Elina Dobreva (Bulgaria); Panayiota Maikanti-Charalampous (Cyprus); Otakar Nyc (Czech Republic); Jørgen Engberg (Denmark); Janne Aittoniemi (Finland); Frédéric Barbut, Catherine Eckert, Hélène Marchandin and Hélène Jean-Pierre (France); Mathias Herrmann, Barbara Gärtner, Fabian Berger, Lutz von Müller, Reinier Mutters, Sören Schubert and Jana Bader (Germany); Maria Orfanidou, Stavroula Smilakou and Ioannis Deliolanis, Eleni Malamou-Lada (Greece); Elisabeth Nagy, Edit Urban, Zsuzsanna Barna and Katalin Kristóf (Hungary); Mairead Skally, Fidelma Fitzpatrick, Lynda Fenelon, Frank Dennehy and Katharina Stein (Ireland); Paola Mastrantonio, Patrizia Spigaglia, Claudio Farina, Francesca Vailati, Marco Passera, Luca Masucci, Maurizzio Sanguinetti, Domenico Nagel, Gianluca Quaranta, Rosalia Graffeo, Teresa Zaccaria, Giovanni Gesu and Maria Chiara Sironi (Italy); Arta Balode (Latvia); Hanna Pituch (Poland); Mónica Oleastro (Portugal); Elena Nováková, Vladimíra Sadloňová and Jana Kompaníková (Slovakia); Maja Rupnik and Sandra Janežič (Slovenia); Emilio Bouza, Elena Reigadas, Luis Alcalá, Josefina Liñares, Fe Tubau and Jordi Niubo (Spain); Torbjörn Norén (Sweden); Andreas Widmer, Reno Frei, Adrian Egli, Martin Altwegg and Livia Berlinger (Switzerland); Ed Kuijper and Celine Harmanus (The Netherlands); Derek Fairley (UK-N. Ireland); James McKenna, Henry Mather, John Coia (UK-Scotland), Trefor Morris (UK-Wales), David Griffiths, Derrick Crook, Irene Monahan and Tim Planche (UKEngland).

We are grateful to Warren Fawley, Peter Parnell, Emma Best and Paul Verity at CDRN Leeds for performing PCR ribotyping and assignments. We would like to thank Chris Longshaw for his substantial contributions to the study. We would like to thank the ESCMID Study Group for Clostridium difficile (ESGCD) for their professional support.

Medical writing support was provided by Iona Easthope of Cello Health MedErgy, funded by Astellas Pharma, Inc.

These data were presented in part as a poster at the 28th European Congress of Clinical Microbiology and Infectious Diseases (ECCMID), Madrid, Spain, 21-24 April 2018.

Author contributions and declaration The material is original and has not been published elsewhere. The data were presented in part as a poster presentation (no. P1843) at the 28th ECCMID, 21-24 April 2018, Madrid, Spain. All primary authors have made substantive intellectual contributions to the manuscript, approved the final version for submission and are able to account for its content. The participants of the Study Group submitted $C$. difficile isolates or toxin-positive faecal samples for testing. All applicable parts of the STROBE guidelines were followed in the reporting of this study.

Funding This study was initiated and supported by Astellas Pharma, Inc. Medical writing support was funded by Astellas Pharma, Inc. 


\section{Compliance with ethical standards}

Conflict of interest JF has received grants from Summit Therapeutics, Melinta and Morphochem.

MHW has received grants and consultancy fees from Abbott, Actelion, Alere, Astellas, bioMerieux, Cerexa, Cubist, Da Volterra, the European Tissue Symposium, MedImmune, Optimer, Pfizer, Qiagen, Sanofi-Pasteur, Summit, Synthetic Biologics and Valneva and consultancy fees from Astra Zeneca, Basilea, Durata, The Medicine Company, Merck, Nabriva, Pfizer, Roche and Seres.

JAPF is an employee of Astellas Pharma, Inc. and has a patent EP17167541.6 pending to Astellas Pharma Europe Ltd.

All other authors have no conflict of interest to declare.

Ethical approval This article does not contain any studies with human participants performed by any of the authors.

Access to data Access to anonymised individual participant level data will not be provided for this trial as it meets one or more of the exceptions described on www.clinicalstudydatarequest.com under "Sponsor Specific Details for Astellas."

Open Access This article is distributed under the terms of the Creative Commons Attribution 4.0 International License (http:// creativecommons.org/licenses/by/4.0/), which permits unrestricted use, distribution, and reproduction in any medium, provided you give appropriate credit to the original author(s) and the source, provide a link to the Creative Commons license, and indicate if changes were made.

\section{References}

1. Baines SD, O'Connor R, Freeman J, Fawley WN, Harmanus C, Mastrantonio P, Kujper EJ, Wilcox MH (2008) Emergence of reduced susceptibility to metronidazole in Clostridium difficile. J Antimicrob Chemother 62:1046-1052. https://doi.org/10.1093/ jac/dkn313

2. Barbut F, Mastrantonio P, Delmée M, Brazier J, Kuijper E, Poxton I, Ackermann G, Bouza E, Balmelli C, Drudy D, Ladas H, Nagy E, Pituch H, Wullt M, Yucesoy M, Rupnik M (2007) Prospective study of Clostridium difficile infections in Europe with phenotypic and genotypic characterisation of the isolates. Clin Microbiol Infect 13:1048-1057. https://doi.org/10.1111/j.1469-0691.2007.01824.x

3. Bauer MP, Notermans DW, van Benthem BH, Brazier JS, Wilcox MH, Rupnik DL, Monnet JT, Van Dissel JT, Kuijper EJ (2011) Clostridium difficile infection in Europe: a hospital-based survey. Lancet 377:6373. https://doi.org/10.1016/S0140-6736(10)61266-4

4. Clinical and Laboratory Standards Institute (2012) Methods for antimicrobial susceptibility testing of anaerobic bacteria, 8th edn. CLSI, Wayne

5. Cornely OA, Crook DW, Esposito R, Poirier A, Somero MS, Weiss K, Sears P, Gorbach S (2012) Fidaxomicin versus vancomycin for infection with Clostridium difficile in Europe, Canada, and the USA: a double-blind, non-inferiority, randomised controlled trial. Lancet Infect Dis 12:281-289. https://doi.org/10.1016/S14733099(11)70374-7

6. Davies KA, Ashwin H, Longshaw CM, Burns DA, Davis GL, Wilcox MH (2016) Diversity of Clostridium difficile PCR ribotypes in Europe: results from the European, multicentre, prospective, biannual, point-prevalence study of Clostridium difficile infection in hospitalised patients with diarrhoea (EUCLID), 2012 and 2013.
Euro Surveill 21:30294. https://doi.org/10.2807/1560-7917.ES. 2016.21.29.30294

7. European Medicines Agency (2011) Assessment report: Dificlir. http://www.ema.europa.eu/docs/en_GB/document_library/ EPAR - Public assessment report/human/002087/ WC500119707.pdf. Accessed 22 Feb 2019

8. Freeman J, Bauer MP, Baines SD, Corver J, Fawley WN, Goorhuis B, Kujper EJ, Wilcox MH (2010) The changing epidemiology of Clostridium difficile infections. Clin Microbiol Infect 23:529-549. https://doi.org/10.1128/CMR.00082-09

9. Freeman J, Vernon J, Morris K, Nicholson S, Todhunter S, Longshaw C, Wilcox MH, Pan-European Longitudinal Surveillance of Antibiotic Resistance among Prevalent Clostridium difficile Ribotypes' Study Group (2015) PanEuropean longitudinal surveillance of antibiotic resistance among prevalent Clostridium difficile ribotypes. Clin Microbiol Infect 21: e9-e16. https://doi.org/10.1016/j.cmi.2014.09.017

10. Freeman J, Vernon J, Pilling S, Morris K, Nicholson S, Shearman S, Longshaw C, Wilcox MH (2018) The ClosER study: results from a three-year Pan-European longitudinal surveillance of antibiotic resistance among prevalent Clostridium difficile ribotypes, 20112014. Clin Microbiol Infect 24:724-731. https://doi.org/10.1016/j. cmi.2017.10.008

11. Goldstein EJC, Citron DM, Sears P, Babakhani F, Sambol SP, Gerding DN (2011) Comparative susceptibilities to fidaxomicin (OPT-80) of isolates collected at baseline, recurrence, and failure from patients in two phase III trials of fidaxomicin against Clostridium difficile infection. Antimicrob Agents Chemother 55: 5194-5199. https://doi.org/10.1128/AAC.00625-11

12. Janezic S, Indra A, Allerberger F, Rupnik M (2011) Use of different molecular typing methods for the study of heterogeneity within Clostridium difficile toxinotypes V and III. J Med Microbiol 60: 1101-1107. https://doi.org/10.1099/jmm.0.031054-0

13. Leeds JA (2016) Antibacterials developed to target a single organism: mechanisms and frequencies of reduced susceptibility to the novel anti-Clostridium difficile compounds fidaxomicin and LFF571. Cold Spring Harb Perspect Med 6:1-14. https://doi.org/ 10.1101/cshperspect.a025445

14. Louie TJ, Cannon K, Byrne B, Emery J, Ward L, Eyben M, Krulicki W (2012) Fidaxomicin preserves the intestinal microbiome during and after treatment of Clostridium difficile infection (CDI) and reduces both toxin re-expression and recurrence of CDI. Clin Infect Dis 55(Suppl 2):S132-S142. https://doi.org/10. 1093/cid/cis338

15. Louie TJ, Miller MA, Mullane KM, Weiss K, Lentnek A, Golan Y, Gorbach S, Sears P, Shue Y-K (2011) Fidaxomicin versus vancomycin for Clostridium difficile infection. N Engl J Med 364:422431. https://doi.org/10.1056/NEJMoa0910812

16. Marín M, Martín A, Alcalá L, Cercenado E, Iglesias C, Reigadas E, Bouza E (2015) Clostridium difficile isolates with high linezolid MICs harbor the multiresistance gene cfr. Antimicrob Agents Chemother 60:4428. https://doi.org/10.1128/AAC.04082-14

17. Miller M, Gravel D, Mulvey M, Taylor G, Boyd D, Simor A, Gardam M, McGeer A, Hutchinson J, Moore D, Kelly S (2010) Health care-associated Clostridium difficile infection in Canada: patient age and infecting strain type are highly predictive of severe outcome and mortality. Clin Infect Dis 50:194-201. https://doi.org/ $10.1086 / 649213$

18. Office for National Statistics (2012) Deaths involving Clostridium difficile: England and Wales, 2012. Newport, South Wales. http:// www.ons.gov.uk/peoplepopulationandcommunity/ birthsdeathsandmarriages/deaths/bulletins/ deathsinvolvingclostridiumdifficileenglandandwales/2013-08-22

19. Schwanbeck J, Riedel T, Laukien F, Schober I, Oehmig I, Zimmermann O, Overmann J, Groß U, Zautner AE, Bohne W (2018) Characterization of a clinical Clostridioides difficile isolate 
with markedly reduced fidaxomicin susceptibility and a V1143D mutation in rpoB. J Antimicrob Chemother 74:6-10. https://doi. org/10.1093/jac/dky375

20. Sears P, Crook DW, Louie TJ, Miller MA, Weiss K (2012) Fidaxomicin attains high fecal concentrations with minimal plasma concentrations following oral administration in patients with Clostridium difficile infection. Clin Infect Dis 55(Suppl 2):S116S120. https://doi.org/10.1093/cid/cis337

21. Spigaglia P (2016) Recent advances in the understanding of antibiotic resistance in Clostridium difficile infection. Ther Adv Infect Dis 3:23-42. https://doi.org/10.1177/2049936115622891

22. Spigaglia P, Barbanti F, Dionisi AM, Mastrantonio P (2010) Clostridium difficile isolates resistant to fluoroquinolones in Italy: emergence of PCR ribotype 018. J Clin Microbiol 48:2892-2896. https://doi.org/10.1128/JCM.02482-09
23. Stubbs SLJ, Brazier JS, O’Neill GL, Duerden BI (1999) PCR targeted to the 16S-23S rRNA gene intergenic spacer region of Clostridium difficile and construction of a library consisting of 116 different PCR ribotypes. J Clin Microbiol 37:461-463

24. Surawicz CM, Brandt LJ, Binion DG, Ananthakrishnan AN, Curry SR, Gilligan PH, McFarland LV, Mellow M, Zuckerbraun BS (2013) Guidelines for diagnosis, treatment, and prevention of Clostridium difficile infections. Am J Gastroenterol 108:478-498. https://doi.org/10.1038/ajg.2013.4

Publisher's note Springer Nature remains neutral with regard to jurisdictional claims in published maps and institutional affiliations. 